\title{
A qualitative study of adherence to nutritional treatment: perspectives of patients and dietitians
}

\author{
This article was published in the following Dove Press journal: \\ Patient Preference and Adherence \\ 4 February 2014 \\ Number of times this article has been viewed
}

\section{Ronit Endevelt \\ Anat Gesser-Edelsburg}

School of Public Health, University of Haifa, Mount Carmel, Haifa, Israel
Correspondence: Ronit Endevelt School of Public Health, University of Haifa, Mount Carmel, Haifa 31905, Israel

Tel +9724828 8675

Fax +972 48288637

Email rendevelt@univ.haifa.ac.il
Background: Effective interaction between care providers and patients is crucial for the success of most medical treatments; in nutritional medical treatment, it is of paramount importance. The aim of the present study was to ascertain the role of the dietitian-patient relationship and the counseling approach in influencing individual patient decisions to adhere to counseling by persisting with nutritional treatment.

Methods: We conducted focus groups with two types of patients, namely, those who had consulted dietitians only once and those who had attended at least three appointments. We divided these two groups into 12 focus groups. In addition, in-depth interviews were held with 17 clinical dietitians. Our qualitative research was based on the perceptions of patients and dietitians.

Results: When the encounter between the dietitian and the patient followed the standard educational and informative approach, both the short-term nature of the interaction and the absence of an individualized therapeutic program discouraged patients from persisting with treatment. In contrast, the counseling and therapeutic nutritional approach promoted nutritional guidance through broader behavioral and lifestyle therapies. This approach appears more appropriate for chronically ill patients. The dietitians and some of the patients understand that the profession is changing from the informative and educational approach to a therapeutic counseling approach, but it is difficult for them to adapt to the new model.

Conclusion: Most patients appear to want individualized, not standardized, treatment. In order to change patients' eating patterns, dietitians must adopt a more therapeutic approach and relate to patients' cultural needs and desires to achieve sustainable results.

Keywords: therapeutic counseling approach, nutrition educational approach, treatment, nutritional

\section{Introduction}

Effective interaction between dietitians and patients is crucial for the success of the nutritional counseling process. Dietetics combines the health and disease sciences with the understanding of food composition and the various economic, social, psychological, and physiological factors that influence nutritional behavior, ${ }^{1}$ with a focus on turning theoretical information and abstract ideas about a nutritional lifestyle into concrete actions and practical behavioral skills for clients. ${ }^{2}$ The patient's trust in the dietitianpatient relationship is also crucial for the success of the intervention. ${ }^{3}$

Although the nutritional counseling literature is extensive, ${ }^{4}$ empirical studies have mainly focused on the ultimate effectiveness of counseling and not on the relationship between patient and dietitian over the course of treatment. ${ }^{5}$ There are several Australian and British studies that have researched the quality of life in clients 
receiving medical nutrition therapy, mainly in order to assess dietitians' effectiveness in changing eating behaviors. ${ }^{6-8}$

Maccabi Health Services (MHS) has 1.9 million insured patients who have access to 270 dietitians throughout Israel. According to Israeli health laws, a patient who is entitled to nutritional counseling can receive between four and 14 nutritional counseling visits in a calendar year, depending on the diagnosis. The counseling is conducted in a face-to-face counseling setting in outpatient clinics. The first visit lasts at least 30 minutes, and follow-up visits last about 15 minutes. More than $80 \%$ of the patients who consult dietitians have chronic diseases, such as diabetes, cardiovascular diseases, obesity, and dyslipidemia, that require long-term nutritional education and counseling programs. Nevertheless, over the last 2 years, there has been a rise in the number of patients who fail to come to their followup sessions after their first visit to a dietitian. Such a lack of attendance may indicate a lack of adherence to treatment. During this period, $40 \%-50 \%$ of all patients who started nutritional counseling did not return after their first visit, although they were entitled to do so free of charge. This number represents a sharp increase over the previous number of patients $(20 \%-30 \%)$ (MACCABI data base [computerized medical file]) who failed to come to their follow-up sessions between 2009 and 2011.

It is well known that, in the case of chronic diseases, short-term nutritional counseling is of much less value than continued nutritional care, and that $70 \%$ of patients would be better served by continued nutritional care. ${ }^{9-11}$ Several studies on the clinical role of dietitians have delineated the challenging nature of the relationship between dietitians and patients. $7,12,13$ The complexity of this interaction led MHS to investigate why some patients choose to continue with counseling whereas others opt to terminate their counseling after only one consultation.

The aim of the present study was to ascertain the role of the dietitian-patient relationship and the counseling approach in influencing individual patients' decisions to adhere to treatment by continuing or not to adhere by terminating their nutritional treatment. In order to address this goal, we focused on the perceptions of both patients and dietitians with regard to the dietitian's role in the counseling process.

\section{Methods}

\section{Study design and analysis}

The study was based on discussions within patient focus groups and on one-on-one interviews with dietitians, using a qualitative description approach. ${ }^{14}$ Audio-recorded semistructured interviews were carried out, and the resulting data were analyzed according to Strauss and Corbin's framework for qualitative data analysis. ${ }^{15}$ All of the participants provided their informed consent, and MHS's ethical committee approved this study.

\section{Study samples}

We used extreme-case sampling, ${ }^{16}$ recruiting participants who complied with the recommended attendance at nutritional counseling sessions and those who did not. These participants belonged to the same focus groups. Using the MHS's data registry from 2011, we collected information on the number of each patient's consultations with dietitians. Twelve focus groups of patients were recruited, including participants who had come to only a single appointment with a dietitian (six groups) and others who had come to at least three appointments in 2011 (six groups). We chose at least three appointments because this is greater than the average number of visits to a dietitian (2.2 consultations), according to the MHS statistics (MACCABI data base). Eighty percent of the patients we approached agreed to participate in the focus groups.

The rationale for this approach stemmed from our research objective, which was to understand the barriers that influenced the decision not to return after a first visit for continued nutritional counseling with a dietitian. Given that previous studies have established that adherence to a recommended treatment regimen is associated with continuity of care with the dietitian, ${ }^{17-19}$ we also asked those patients who had come to at least three appointments what motivated them to continue to come back for follow-up sessions with the dietitian.

The participants in the focus groups included patients who consulted dietitians for various reasons, ranging from obesity to other chronic diseases, such as diabetes and cardiovascular disease. The study's population included different subpopulations with diverse sociodemographic characteristics, religious affiliations, and languages, comprising five groups of nonreligious, Hebrew-speaking Jewish men and women, five groups of Arabic-speaking Muslims (two allmale groups and three all-female groups), and two groups of Hebrew-speaking, ultra-orthodox Jewish women from low socioeconomic backgrounds. The ages of the participants in the focus groups ranged from 35 to 60 years.

The members of the focus groups were told that the subject of the focus groups would be their lifestyles. For example, the participants were asked what they thought about nutrition and physical activity, about the differences between nutritionists and other health professionals, and their opinions about dietitians and their experiences with them. To avoid influencing the groups' discussions in order to preempt a "social compliance" effect (group influence to conform to one particular idea, if they knew in advance the purpose of 
the discussion $)^{20}$ and promote maximum reliability, we did not specify to participants the purpose of the study nor the fact that they had been chosen because they had attended either only one or more than three visits to a dietitian. Each participant received 100 Israeli shekels (approximately US\$30) as an incentive for participating.

In addition, in-depth interviews were held with 12 clinical dietitians who volunteered to participate with the understanding that the results of the study would be published without their being mentioned by name. These MHS-employed dietitians work with low to middle socioeconomic patient populations in central and southern Israel. The clinical dietitians were recruited directly by MHS's district dietitians. Five interviews were also held with MHS district dietitians who supervise the clinical dietitians from each district.

\section{Data collection}

Semi-structured questionnaires were composed for each group of interviewees: the patients, the clinical dietitians, and the district dietitians. The semi-structured questions for the interviews with the patients focused on the significance they attached to health and its priority in their lives; what they considered "good nutrition"; their motivations for consulting a dietitian; how they perceived what dietitians do; the role of their primary care physician in promoting nutrition counseling; how they perceived the dietitian's professional proficiency and the quality of their consultation; the barriers (therapeutic, communicative) that led them to terminate treatment; and how they thought those barriers could be reduced.

The semi-structured questions for the dietitians took 1 hour to complete and investigated how they perceived their profession; how they perceived the dietitian-patient relationship; what they thought were the barriers that discouraged patients from returning; and what they thought could be improved to make patients persist in the counseling process.

The semi-structured questions for the district dietitians at MHS focused on how they perceived their profession; the barriers they thought discouraged patients from continuing treatment; their interpretation of the findings from the interviews with the patients and the clinical dietitians; and how they thought the barriers could be reduced to stimulate prolonged counseling with dietitians.

\section{Summary of the recruitment population study}

The focus groups and the personal interviews were supervised by two project researchers and conducted by three trained moderators. The trained moderators were psychologists who, together with the researchers, analyzed the data in order to ensure validity and reliability. The focus group discussions lasted from 60 to 90 minutes, and the interviews with the district dietitians lasted from 45 to 60 minutes. The focus groups and interviews were audiorecorded and transcribed verbatim, and those in Arabic were translated into Hebrew. Transcripts were reviewed for accuracy in transcription. Another validity confirmation method we applied was to share the results with the dietitians themselves in order to receive their feedback by a reflective process. ${ }^{21}$ Two psychologists, a social-marketing specialist, and senior dietitians analyzed the data in order to categorize them into themes.

\section{Data analysis}

A content analysis approach ${ }^{22}$ was used for data analysis. This process involved several distinct stages, beginning with familiarization with the data. The narratives from the different participant groups were separately analyzed to determine the major themes. Then themes from each group were compared with regard to the main objective of the study. Conducting this analysis involved indexing and sifting through the data and sorting the quotes from patients, dietitians, and district dietitians; charting or selecting quotes and placing them in the appropriate thematic category; comparing the findings in all three groups with regard to the research topic; and making a final interpretation.

\section{Results}

The most dominant theme we found was the perception of the dietitian-patient encounter. We divided the results into four sub-themes, as follows:

1. Patients' perceptions of dietitians and the physician's role in shaping these perceptions.

2. How district dietitians understand the patients' perceptions of their profession.

3. Dietitians' perceptions of their profession.

4. Barriers to the long-term counseling process.

\section{Patients' perceptions of dietitians and the physician's role in shaping these perceptions}

When participants in the patient focus groups were asked how they perceived what dietitians do, most of them described dietitians as nutrition experts; however, many did not know what kind of education dietitians received - whether medical or paramedical (nonclinical) - nor the difference between a 
dietitian and other nutritional counselors, such as naturopaths. For example, one patient noted:

It says certified dietitian so this must mean something [...].

Where do you study that?

The participants indicated that the physician's role in referring patients to dietitians is a strong factor in the patient's decision to continue the counseling. A physician's encouragement or ambivalent attitude affected the decision to continue or terminate treatment.

The dietitian's profession and form of intervention were described in the patient focus groups, both in terms of short-term educational and informational dietary counseling and/or long-term therapy that includes behavioral guidance. One participant described counseling as follows:

I look at it as an informative interaction because it is brief [...]. She should explain and tell me what to do and ensure that it works and that's all. Two or three meetings and that's it. It's not a treatment that requires continuity and close monitoring.

Another said of the role of the dietitian:

I think it is a kind of therapy. There is follow-up and changes and adjustments over time [...]. I do not see it as a one-time thing.

Sometimes the concepts of educational interaction and counseling treatment were intermixed when interviewees attempted to define the dietitian's profession, with additional concepts affixed to the notion of therapy, such as "psychotherapist" (sometimes part of the nutritional treatment has psychological aspects). The consultation and patient-dietitian interaction had a significant impact on conceptions of the dietitian's role and also influenced the patient responses to educational counseling and the extent of commitment and adherence to the treatment plan:

She was like a food behavior psychologist [...].

\section{How do district dietitians understand the patients' perceptions of their profession?}

The interviews with MHS's district dietitians addressed how they think patients perceive dietitians. They were aware of patients' perceptions of their field. One respondent noted that "The issue of "Who is this dietitian who is treating me? Can I trust her? Does she have specific behavioral training?' has an effect on the treatment." In addition, the district dietitians indicated that they worked with the dietitians toward more behavioral and less technical treatment. They taught their dietitians motivational interviewing techniques, cognitive behavioral treatment, and goal setting. Nevertheless, they were skeptical about the extent to which this instruction had any effect on the dietitians and the degree to which they applied it in practice "because it has not yet been integrated into the profession".

\section{Dietitians' perceptions of their profession}

According to what was portrayed in most of the interviews, the dietitians' formal education and professional socialization focused on clinical, nutritional counseling, not on behavioral counseling:

The degree is clinical. There is hardly even one course about

how to effect change in a patient.

Most of the dietitians interviewed said that their work focused on educational and informative counseling about nutrition and providing the patient with information on nutrition management. Appointments revolve around menu instructions and weighing in, when the goal being weight loss or solving nutritional issues that have medical implications. These professional norms emphasize counseling patients about their nutrition and largely disregard the patient's personality, psychological needs, and lifestyle.

In the interviews, dietitians said that these norms were undergoing a significant and ongoing transformation, moving increasingly toward incorporating emotional behavioral therapy, an approach that involves addressing psychological issues rather than merely instructing the patient regarding nutritional issues. In the interviews, the dietitians changed their professional behaviors from predominantly educational to include more counseling with psychological tools. Some of the dietitians used the term "nutritional psychotherapy" in this context. Some referred to the newer approach as a kind of "coaching" involving close support and guidance, drastically different from offering only a nutritional solution:

There has been a development of the psychological aspect, coaching, which was not in our BA studies.

Most of us took behavioral courses after receiving our university degrees.

According to the dietitians themselves, in terms of the goal of the newer combined nutritional and therapeutic approach, dietitians should focus less on achieving shortterm nutritional goals and more on guiding lifestyle changes. 
Doing so would require the creation of a therapeutic program that defines each side's obligations.

Table 1 compares the informative and educational approach with the counseling approach. As the table shows, the new approach in the profession is more holistic and behavioral. It deals with the challenge of sustainable changes with the patients as partners in the goal setting and in the new program of nutrition behavior.

\section{Barriers to long-term counseling}

When patients described experiences with dietitians whom they defined as "educators" or with sessions they described as "informative", they noted that the treatment was brief and focused. They expected minor interventions to provide guidance, training, or tips, but not follow-up care. In this case, the interaction was perceived as limited, and the patient was responsible for ensuring success. Some of the patients indicated that the informative and educational approach was a barrier that prevented them from returning to the dietitian.

In contrast, when the patients in the focus groups defined the role of the dietitian as a kind of therapist, providing patients with nutritional and behavioral guidance adjusted to the circumstances of the individual's life constraints, such as emotional eating, the contract between the patient and the dietitian was construed as long term. The patients also indicated that a physician's recommendation to consult with a dietitian was important to adherence to the treatment:

If the physicians say that this is a very good dietitian and that every patient I send gets very good results, the patient will continue treatment. However, if the physician says here is a dietitian you can go to, but between you and me, it is better to take medication, then even if the patient consults with the dietitian, he is unlikely to continue after the first visit.

Table 2 provides a description of the barriers to long-term treatment caused by the interaction between the expectations of the dietitian and the patient.

We also found that patients know little about the education and skills of dietitians. They do not know the difference between nutritional coaches who train for one semester and dietitians who have a BA and sometimes graduate degrees (MSc or $\mathrm{PhD}$ ) in nutritional science and dietetics.

Table I Selected qualitative comments from focus groups presenting a comparison between the educational and informative approach and the counseling and treatment approach

\begin{tabular}{|c|c|c|}
\hline Features & Educational and informative approach & Counseling and therapeutic approach \\
\hline Professional description & $\begin{array}{l}\text { Clinical aspect oriented: } \\
\text { "When the profession began } 30 \text { years ago, } \\
\text { it wasn't like this. We knew that a person came in } \\
\text { with a sickness and you had to tell him what he could } \\
\text { and couldn't eat." (Dietitian) }\end{array}$ & $\begin{array}{l}\text { Clinical and holistic behavioral aspects: } \\
\text { "Today it is important for us to see how the } \\
\text { patient relates to food, what it means to him, } \\
\text { what need it fills. It might be an emotional } \\
\text { need in reaction to boredom or stress [...]. } \\
\text { Some eating problems have a psychological } \\
\text { basis and as a therapist, I need to take that } \\
\text { into account and have the tools to address it." } \\
\text { (Dietitian) }\end{array}$ \\
\hline Duration of the interaction & $\begin{array}{l}\text { Short term and focused: } \\
\text { "I treat it as counseling or guidance because it is short-term. } \\
\text { She has to explain, give my instructions and see that } \\
\text { it works and that's it. Two or three meetings are enough. } \\
\text { It is not therapy that requires continuity and close } \\
\text { monitoring." (Patient) }\end{array}$ & $\begin{array}{l}\text { Sustained: } \\
\text { "I feel it is like a psychology of food behavior, } \\
\text { she is very understanding, and I feel I need } \\
\text { ongoing support." (Patient) }\end{array}$ \\
\hline $\begin{array}{l}\text { Relationship between dietitian } \\
\text { and patient }\end{array}$ & $\begin{array}{l}\text { Patient's responsibility: } \\
\text { "The dietitian tells me what's good for me and what I should } \\
\text { eat and that's it }[\ldots] \text {. I'm the one that has to do it }[\ldots] \text {. } \\
\text { So it's not treatment }[\ldots] \text {. (Patient) }\end{array}$ & $\begin{array}{l}\text { Partnership: } \\
\text { "From the beginning I had the feeling of a } \\
\text { partnership. She said, 'Let's try this together, } \\
\text { let's do it at your pace, I don't want to dictate } \\
\text { things that don't suit you [...]. I want us to } \\
\text { succeed.' As if it was about both of us." (Patient) }\end{array}$ \\
\hline Level of involvement & $\begin{array}{l}\text { Dietitian as an expert advisor: } \\
\text { "She has no enthusiasm; it's just a job }[\ldots] \text {. She gives me } \\
\text { instructions and I carry them out }[\ldots] \text {. I realized I needed } \\
\text { a more enthusiastic temperament }[\ldots] \text {. To give me the feeling } \\
\text { that we were working together, that my success was her } \\
\text { professional success." (Patient) }\end{array}$ & $\begin{array}{l}\text { Dietitian as behavioral coach: } \\
\text { "After I had plateaued for a while, she } \\
\text { encouraged me not to give up and to keep at } \\
\text { it and two weeks ago when I managed to lose } \\
\text { a little weight, she was so happy, as if she had } \\
\text { gotten good news, and she said 'great, let's } \\
\text { plan how to proceed.' Her enthusiasm gave } \\
\text { me a lot of strength to go on." (Patient) }\end{array}$ \\
\hline
\end{tabular}


Table 2 Selected comments from the focused groups regarding barriers to long-term treatment

When dietary counseling was seen as a one-time event rather than as a process

"What I wanted in the first place was to receive information, to know what is allowed, what is healthy and what is not [...]. She guided me and that was enough for me. I did not see a need to go back to her."

When the patient thinks that the issue was adequately addressed after one meeting

One patient said: "The patient does not return [...] because he does not think that in future meetings he can learn anything more than he has already learned." This argument was repeated in some of the interviews in a critical tone. For example: "After a month I said: 'I went there twice and both meetings were the same.' I said to myself: 'It's enough."

Routine counseling

Some of the interviewees noted that they found the advice they received from the dietitian generic. For example: "They make a basic, standard menu of what you are and are not allowed to eat, don't ask me how I am and what is good for me [...]. It was just standard [...]. Here is the menu and that's it, as if handing out the menu were everything." Patients reported that they terminated treatment when the diet offered was not adjusted to their lifestyle: "It is hard for me because I cook, I have a busy day and I just eat whatever there is, and she demanded I change everything [...].

She wanted me to write down what I eat, when and why, and at the same time to give up a lot of things I am used to and like [...]. It was more than I could handle [...]. It was black and white."

Incompatibility at the level of dietary counseling

One of the main reasons patients do not return to the dietitian after the first meeting is the patient's feeling that the nutritional solution offered is not individualized: "She had a motto and I was supposed to go along with it [...]. How could I eat every two hours at work? I did not feel there was an attempt to adjust the diet to my lifestyle."

Lack of empathy

Some of the patients said they terminated treatment because the dietitian was too "business-like" and not supportive enough emotionally: "It was like working with a robot that weighs you and gives you a pass/fail grade."

Lack of intensive follow-up

Some patients said they terminated treatment when their need for a more intensive framework was not met. For example: "Without an intensive regime I break down and that is what happened after I waited more than a month between appointments." Some participants mentioned that scheduling appointments was difficult and that the appointments were too brief. Participants used the term "five minutes with the dietitian" to describe meetings that were too short to be satisfying or serious.

\section{Discussion}

The results of this study show that the continuity of the nutritional counseling process depends on many aspects of the interaction with the dietitian and previous expectations before and at the first meeting. Psychological, physical, cultural, and normative barriers can be obstacles to behavioral changes, especially nutritional ones. In this study, we found that, in addition to those barriers that affect compliance and perseverance, there are unique barriers at play in the context of the nutritional counseling process and the dietitian-patient interaction.

Our findings indicate that, when the encounter between dietitian and patient emphasizes primarily information, patients terminate counseling after a short time. It is important to mention that, for some patients, the informative and educational approach is sufficient, especially if it is consistent with their expectations and if their health concerns are limited (for example, with issues such as anemia, constipation, etc). The case is different with regard to obesity and chronic diseases, when there is a need for the continuity of the counseling process. The patients understand that, when there is a need for continuity of care, they need a more psychological and behavioral approach.

The interviews indicate that dietitians also understand the overall need to move beyond the informative approach to more behavioral ones, as the literature suggests. ${ }^{23,24}$ Dietitians and the district dietitians described the transformation in their field from an emphasis on informative educational skills to a more therapeutic approach, but indicated that sometimes it was difficult to adapt to this change; their training tended to focus on scientific and medical educational treatment rather than on the psychological element, but they now must also try to promote the patients nutrition behavior and psychology in an holistic approach. Other health care providers, such as family physicians, must also be psychologically attuned to their patients, but this is especially critical for dietitians, because they promote and stimulate lifelong changes in eating behaviors and physical activity. ${ }^{25-27}$ The results also establish that the physician's referral and unequivocal recommendation are very important, as seen in previous literature..$^{28}$

Although another study shows that the most effective professionals in changing nutritional behaviors are dietitians, patients are not sufficiently aware of this fact and of the educational background of the dietitians. ${ }^{29}$ The findings in our study, and previous studies, also indicate that there is a link between the active encouragement of the referring physician and persistence in nutritional counseling. 
Dietitians are aware of the transformation within their profession. They know that they must assess, understand, and then work to positively influence people's attitudes, values, beliefs, and interests in order to help them recognize nutrition as a determinant of better health. They must help their patients to adopt new nutritional behaviors and add physical activity to their lifestyle. As other studies have demonstrated, a variety of nutritional and behavioral skills are needed in order to convince patients continue with the counseling process. ${ }^{7,30,31}$ Future studies should also investigate variations in patients' needs based on their cultural educational, personal characteristics and needs, and pre-existing medical conditions. Thus, the education of dietitians must become more psychologically oriented.

\section{Limitations}

One limitation of this study is that there are categories of patients with additional social, demographic, and ethnic characteristics that were not included and that need more detailed attention, particularly within the Israeli Arab population. Another limitation is the fact that this was a qualitative study that may not be sufficiently representative of all patients.

\section{Conclusion}

Most patients appear to want individualized, not "standardized," treatment. In order to change eating patterns, the dietitian's approach needs to be adapted to the patient's individual and psychological needs, desires, and narrative. This change in the profession should be communicated to the patient to encourage patient compliance. Further research may be necessary to determine whether the transformation in the field of dietetics has occurred and how patients perceive it. Moreover, the scope of this research should be broadened to include additional countries and languages.

\section{Disclosure}

The authors report no conflicts of interest in this work.

\section{References}

1. Cant RP, Aroni RA. Exploring dietitians' verbal and nonverbal communication skills for effective dietitian-patient communication. J Hum Nutr Diet. 2008;21(5):502-511.

2. Cant R, Aroni R. From competent to proficient; nutrition education and counselling competency dilemmas experienced by Australian clinical dietitians in education of individuals. Nutrition and Dietetics. 2008;65(1):84-89.

3. Schwartz NE. Clinical role expectations and performance of dietitians employed in British Columbia hospitals. J Can Diet Assoc. 1981;42(1):48, 50-51, 54-61.
4. Cant RP. Communication competence within dietetics: dietitians' and clients' views about the unspoken dialogue - the impact of personal presentation. J Hum Nutr Diet. 2009;22(6):504-510.

5. Lu AH, Dollahite J. Assessment of dietitians' nutrition counselling self-efficacy and its positive relationship with reported skill usage. J Hum Nutr Diet. 2010;23(2):144-153.

6. Barr J, Schumacher G. Using focus groups to determine what constitutes quality of life in clients receiving medical nutrition therapy: first steps in the development of a nutrition quality-of-life survey. J Am Diet Assoc. 2003;103(7):844-851.

7. Cant R. What outcome measures do Australian dietitians use to evaluate nutrition education interventions with individual patients? Nutrition and Dietetics. 2008;65(4):284-291.

8. Verotti CC, Torrinhas RS, Cecconello I, Waitzberg DL. Selection of top 10 quality indicators for nutrition therapy. Nutr Clin Pract. 2012;27(2):261-267.

9. Franz MJ. Evidence-based medical nutrition therapy for diabetes. Nutr Clin Pract. 2004;19(2):137-144.

10. Pastors JG, Franz MJ, Warshaw H, Daly A, Arnold MS. How effective is medical nutrition therapy in diabetes care? J Am Diet Assoc. 2003;103(7):827-831.

11. Pastors JG, Warshaw H, Daly A, Franz M, Kulkarni K. The evidence for the effectiveness of medical nutrition therapy in diabetes management. Diabetes Care. 2002;25(3):608-613.

12. Nestle M. Leadership in clinical dietetics: meeting the challenge to roles in nutritional support. J Am Diet Assoc. 1984;84(11):1349-1353.

13. Schwartz NE. A study of the clinical role of the dietitian as viewed by allied health professionals. J Allied Health. 1984;13(4):288-298.

14. Neergaard MA, Olesen F, Andersen RS, Sondergaard J. Qualitative description - the poor cousin of health research? BMC Med Res Methodol. 2009;9:52.

15. Strauss A, Corbin J. Basics of Qualitative Research: Techniques and Procedures for Developing Grounded Theory. 2nd ed. Thousand Oaks, CA: Sage Publications; 1998.

16. Patton MQ. Qualitative Research and Evaluation Methods. 2nd ed. Thousand Oaks, CA: Sage Publications; 1990. Available from http:// www.sagepub.com/repository/binaries/pdfs/HistoryofMethods.pdf. Accessed January 4, 2014.

17. Endevelt R, Baron-Epel O, Karpati T, Heymann AD. Does low socioeconomic status affect use of nutritional services by pre-diabetes patients? Int J Health Care Qual Assur. 2009;22(2):157-167.

18. Endevelt R, Baron-Epel O, Viner A, Heymann AD. Socioeconomic status and gender affects utilization of Medical Nutrition Therapy. Diabetes Res Clin Pract. Epub May 20, 2013.

19. Endevelt R, Ben-Assuli O, Klain E, Zelber-Sagi S. The role of dietician follow-up in the success of bariatric surgery. Surg Obes Relat Dis. Epub January 23, 2013.

20. Cialdini RB, Goldstein NJ. Social influence: compliance and conformity. Annu Rev Psychol. 2004;55:591-621.

21. Barbour RS. Checklists for improving rigour in qualitative research: a case of the tail wagging the $\operatorname{dog}$ ? BMJ. 2001;322(7294): 1115-1117.

22. Hsieh HF, Shannon SE. Three approaches to qualitative content analysis. Qual Health Res. 2005;15(9):1277-1288.

23. Thompson RL, Summerbell CD, Hooper L, et al. Relative efficacy of differential methods of dietary advice: a systematic review. Am J Clin Nutr. 2003;77(Suppl 4):1052S-1057S.

24. Wisotsky W, Swencionis C. Cognitive-behavioral approaches in the management of obesity. Adolesc Med. 2003;14(1):37-48.

25. Loxterkamp D. The headwaters of family medicine. $B M J$. 2008;337:a2575.

26. Shakeshaft AM. A study of the attitudes and perceived barriers to undertaking clinical governance activities of dietitians in a Welsh National Health Service trust. J Hum Nutr Diet. 2008;21(3): 225-238. 
27. Stange KC. The paradox of the parts and the whole in understanding and improving general practice. Int $J$ Qual Health Care. 2002;14(4):267-268.

28. Pomeroy SE, Cant RP. General practitioners' decision to refer patients to dietitians: insight into the clinical reasoning process. Aust $J$ Prim Health. 2010;16(2):147-153.

29. Thompson RL, Summerbell CD, Hooper L, et al. Dietary advice given by a dietitian versus other health professional or self-help resources to reduce blood cholesterol. Cochrane Database Syst Rev. 2003;(3):CD001366.
30. Holli BB, Calabrese RJ, O'Sullivan-Maillet J. Communication and Education Skills for Dietetics Professionals. 4th ed. London: Lippincott Williams and Wilkins; 2003.

31. Neumark-Sztainer D, Story M. The use of health behavior theory in nutrition counseling. Top Clin Nutr. 1996;11(2):60-73.

Patient Preference and Adherence

Dovepress

\section{Publish your work in this journal}

Patient Preference and Adherence is an international, peer-reviewed, open access journal focusing on the growing importance of patient preference and adherence throughout the therapeutic continuum. Patient satisfaction, acceptability, quality of life, compliance, persistence and their role in developing new therapeutic modalities and compounds to

optimize clinical outcomes for existing disease states are major areas of interest. This journal has been accepted for indexing on PubMed Central. The manuscript management system is completely online and includes a very quick and fair peer-review system. Visit http://www.dovepress.com/ testimonials.php to read real quotes from published authors. 